\title{
Diversidade genética entre acessos de pimentas e pimentões da Embrapa Clima Temperado
}

\author{
Genetic diversity in peppers and sweet peppers of Embrapa Clima Temperado genebank
}

\author{
Miriam Valli Büttow ${ }^{I}$ Rosa Lía Barbieri ${ }^{I I}$ Raquel Silviana Neitzke ${ }^{\text {III }}$ Gustavo Heiden ${ }^{\text {IV }}$ \\ Fernando Irajá Félix de Carvalho ${ }^{\mathrm{III}}$
}

\section{RESUMO}

Os acessos de pimentas e pimentões (Capsicum annuum L.) da Embrapa Clima Temperado constituem parte dos recursos genéticos de Capsicum. Contudo, é necessário conhecer o quanto esses genótipos são divergentes para que possam ser utilizados em programas de melhoramento. Os objetivos deste trabalho foram avaliar e caracterizar a divergência genética entre os acessos de C. annuum do banco ativo de germoplasma de Capsicum da Embrapa Clima Temperado. Foram caracterizados 20 acessos com base em 36 descritores morfológicos multicategóricos. A diversidade genética foi avaliada por meio do método de agrupamento de Tocher e UPGMA. O método de Tocher formou três grupos de acessos. Pelos critérios utilizados, os dois métodos foram concordantes em agrupar isoladamente o acesso P77, que apresenta caracteres morfológicos particulares em relação aos demais. O estudo realizado evidencia a existência de variabilidade genética moderada entre os 20 acessos de $\boldsymbol{C}$. annuum estudados e apresenta acessos com características ornamentais, os quais podem ser incorporados em programas de melhoramento.

Palavras-chave: Capsicum annuum, descritores morfológicos, recursos genéticos.

\section{ABSTRACT}

Accessions of peppers and sweet peppers (Capsicum annuum) of Embrapa Clima Temperado genebank (Pelotas $R S$ ) integrate Capsicum genetic resources. However, it is necessary to know how much these genotypes are different, so they can be harnessed and used in breeding programs. The aim of this study was to evaluate and characterize genetic

\begin{abstract}
diversity among C. annuum accessions which belongs to Capsicum Embrapa Clima Temperado genebank. Twenty accessions were characterized through 36 multicategorical morphologic descriptors. Genetic diversity was assessed using Tocher grouping method and UPGMA. Three groups of accessions were formed by Tocher. Both methods were in agreement with the isolation of $\mathrm{P} 77$, due to its exclusive morphological traits. The study shows moderate genetic variability among 20 accessions of $C$. annuum studied and introduced accession with ornamental features, which can be incorporated in breeding programs.
\end{abstract}

Key words: Capsicum annuum, morphological descriptors, genetic resources

\section{INTRODUÇÃO}

O gênero Capsicum compreende um grupo diverso de pimentas e pimentões originários da região tropical do continente americano; contudo, atualmente são utilizados por um quarto da população mundial (PICKERSGILL, 1997; BOSLAND \& VOTAVA, 1999; MOREIRA et al., 2006). As pimentas são usadas principalmente para a produção de condimentos, devido a características dos seus princípios ativos, conferindolhes aroma e sabor. O gênero Capsicum (Solanaceae) possui cerca de 25 espécies, classificadas de acordo com o nível de domesticação em domesticadas, semidomesticadas e silvestres. O Brasil é um importante

'Departamento de Genética, Universidade Federal do Rio Grande do Sul (UFRGS), 91501-970, Porto Alegre, RS, Brasil. E-mail: miriamvb@gmail.com. Autor para correspondência.

"Embrapa Clima Temperado, Pelotas, RS, Brasil.

IIIDepartamento de Fitotecnia, Universidade Federal de Pelotas (UFPel), Pelotas, RS, Brasil.

Iv Departamento de Botânica, Universidade de São Paulo (USP), São Paulo, Brasil. 
centro de diversidade para o gênero, já que aqui se encontram representantes nos três níveis de domesticação (CARVALHO et al., 2003). Capsicum annuum é uma das espécies mais cultivadas do gênero e compreende os pimentões, as pimentas doces para páprica, as pimentas picantes (como jalapeño, cayenne, serrano e cereja, entre outras), além de variedades ornamentais (REIFSCHNEIDER, 2000). O pimentão está entre as principais hortaliças cultivadas no país (RUFINO \& PENTEADO, 2006).

Informações a respeito da diversidade de uma coleção de germoplasma servem para aumentar a eficiência dos trabalhos de melhoramento de espécies cultivadas (GELETA et al., 2005). Diversos métodos para medir distância genética, como descritores fenotípicos e marcadores moleculares, têm sido sugeridos em estudos de diversidade das espécies de pimentas e pimentões (TOQUICA et al., 2003 e SUDRÉ et al., 2005). Segundo PICKERSGILL (1997), em pimentão, por exemplo, o nível de heterose está diretamente relacionado com a distância genética entre os genitores, o que torna importante o uso de técnicas adequadas para a estimativa de divergência genética.

As técnicas de análises multivariadas têm sido empregadas para a quantificação da divergência genotípica e fenotípica em várias espécies de hortaliças (COSTA et al., 2006; SUDRÉ et al., 2005). O estudo de divergência permite conhecer o grau de seleção da variabilidade genética das populações vegetais e subsidia a seleção de genitores geneticamente mais divergentes, que poderão ser utilizados em intercruzamentos com possibilidade de aumentar a probabilidade de recuperação de segregantes superiores em gerações avançadas (CRUZ \& CARNEIRO, 2003). Descritores multicategóricos possuem várias opções de classes para o caráter avaliado. A sua coleta é prática, econômica e rápida, em comparação com dados quantitativos e dados moleculares, tornando-os alternativas viáveis para o estudo de bancos e coleções de germoplasma que possuem poucos recursos humanos e financeiros (SUDRÉ et al., 2006).

A Embrapa é responsável por um programa de melhoramento genético de Capsicum, conduzido na forma de rede, que envolve diferentes unidades da empresa nas várias regiões do país. A Embrapa Hortaliças coordena o programa, e a Embrapa Clima Temperado é responsável pelo desenvolvimento de populações, linhagens e cultivares com resistência a doenças e com características agronômicas e industriais superiores às existentes no mercado. Esse processo visa a atender a demanda de consumidores, produtores e empresas de cultivares para consumo in natura e para processamento. Também realiza coleta, caracterização e conservação de germoplasma de Capsicum, ampliando a disponibilidade da sua variabilidade genética.

Portanto, este trabalho teve como objetivos caracterizar e avaliar a variabilidade genética de 20 acessos de Capsicum annuum do banco ativo de germoplasma de Capsicum da Embrapa Clima Temperado, com base em 36 descritores morfológicos multicategóricos.

\section{MATERIAL E MÉTODOS}

No período de 2004 a 2007, foram caracterizados 20 acessos de Capsicum annuum do banco ativo de germoplasma (BAG) de Capsicum da Embrapa Clima Temperado (Tabela 1). Esse BAG possui acessos de diversas espécies de Capsicum: domesticadas, semidomesticadas e silvestres. Para o presente trabalho, foram selecionados todos os acessos de $\boldsymbol{C}$. annuum coletados até o momento. O cultivo foi realizado no campo experimental da Embrapa Clima Temperado, em Pelotas, Rio Grande do Sul (RS), a $31^{\circ} \mathrm{S}$ e $52^{\circ} \mathrm{W}$, em clima subtropical úmido. Foram caracterizadas 10 plantas por acesso, cultivadas com um espaçamento de $0,5 \times 1,0 \mathrm{~m}$. O local de origem dos acessos está indicado na tabela 1 . Foram utilizados 36 descritores morfológicos qualitativos multicategóricos (CARVALHO et al., 2003), com algumas modificações, apresentados a seguir:

(1) cor da haste: verde; verde com estrias violeta; violeta; (2) antocianina nodal: verde; violeta claro; violeta; violeta escuro; (3) formato da haste: cilíndrica; angulada; alada; (4) pubescência da haste: esparsa; intermediária; densa; (5) hábito de crescimento: prostrado; intermediário; ereto; outro; (6) densidade de ramificação: esparsa; intermediária; densa; (7) densidade de folha: esparsa; intermediária; densa; (8) cor da folha: amarelo; verde-claro; verde; verde-escuro; violeta claro; mesclado; verde com antocianina; (9) forma da folha: deltoide; ovalada; lanceolada; (10) pose da flor: pendente; intermediária; ereta; todas; intermediária e ereta; pendente e intermediária; (11) cor da corola: branco; amarelo-claro; amarelo; amarelo esverdeado; violeta com base branca; branco com base violeta; branco com margem violeta; violeta; branco esverdeado; púrpura; branco esverdeado com mancha púrpura; (12) cor da mancha na corola: branco; amarelo; verde amarelado; verde; violeta; sem mancha; (13) forma da corola: rotada; campanulada; intermediária; (14) cor da antera: branco; amarelo; azul pálido; azul; violeta; amarelo com mancha azul claro; (15) cor do filamento: branco; amarelo; verde; azul; violeta claro; 
Tabela 1 - Acessos de Capsicum annuum do banco ativo de germoplasma de Capsicum da Embrapa Clima Temperado caracterizados morfologicamente e utilizados na análise de dissimilaridade genética.

\begin{tabular}{|c|c|c|c|}
\hline Acesso & Nome científico & Nome popular & Procedência \\
\hline $\mathrm{P} 4$ & C. annuum var. annuum & pimenta & Tailândia \\
\hline P5 & C. annuum var. annuum & pimenta & Tailândia \\
\hline P6 & C. annuum var. annuum & pimenta & Tailândia \\
\hline P7 & C. annuum var. gabriusculum & pimenta & Brasil (Renascença, PR) \\
\hline P16 & C. annuum var. annuum & pimenta cayenne (dedo de moça) & Brasil (Cascavel, PR) \\
\hline P22 & C. annuum & pimentinha vermelha & Brasil (Renascença, PR) \\
\hline P31 & C. annuum & pimentão antigo & Brasil (Rio Grande, RS) \\
\hline P39 & C. annuum & pimenta & Brasil (Farroupilha, RS) \\
\hline P43 & C. annuum & pimenta pé-de-cachorro & Brasil (Pedro Afonso, TO) \\
\hline P45 & C. annuum & pimentão & Brasil (Rio Grande, RS) \\
\hline P46 & C. annuum & pimenta & Uruguai (Chuy) \\
\hline $\mathrm{P} 47$ & C. annuum & pimenta & Uruguai (Chuy) \\
\hline P48 & C. annuum & pimenta & Uruguai (Chuy) \\
\hline P51 & C. annuum & pimenta & México \\
\hline P55 & C. annuum var. annuum & pimentão martinica & Martinica \\
\hline P58 & C. annuum & pimenta ornamental & Brasil (São Lourenço do Sul, RS) \\
\hline P76 & C. annuum & pimentão amarelo & México \\
\hline P77 & C. annuum & pimenta negra & México \\
\hline P98 & C. annuum & pimentão & Brasil (Rio Grande, RS) \\
\hline P111 & C. annuum & jalapeño & sem informação de origem \\
\hline
\end{tabular}

violeta; azul violeta; (16) posição do estigma: inserto; mesmo nível; excerto; mesmo nível e excerto; inserto e mesmo nível; inserto e excerto; (17) pigmento do cálice: ausente; presente; (18) margem do cálice: inteiro; intermediário; dentado; (19) constrição anelar do cálice: ausente; presente; (20) cor do fruto imaturo: branco; amarelo; verde; laranja; violeta; violeta escuro; amarelo esverdeado; verde amarelado; branco amarelado; marrom; (21) cor do fruto maduro: branco; amarelo limão; amarelo laranja pálido; amarelo laranja; laranja pálido; laranja; vermelho claro; vermelho; vermelho escuro; violeta; marrom; preto; amarelo; amarelo pálido; (22) formato do fruto: alongado; arredondado; triangular; campanulada; retangular; (23) comprimento do fruto (cm): até $1 ;>1$ a $2 ;>2$ a 4 ; > 4 a 8 ; > 8 a 12 ; acima de 12; (24) largura do fruto (cm): até $1 ;>1$ a 2,5; > 2,5 a 5 ; $>5$ a 8 ; acima de 8 ; (25) comprimento do pedúnculo (cm): até $2 ;>2$ a 4 ; $>4$ a 6 ; acima de 6; (26) espessura da parede (mm): até $1 ;>1$ a $2 ;>2$ a 3 ; > 3 a $4 ;>4$ a 5 ; acima de 5; (27) ombro do fruto: agudo; obtuso; truncado; cordato; lobado; (28) formato da ponta do fruto: pontiagudo; truncado (blunt); afundado; afundado com ponta; (29) apêndice na ponta do fruto: ausente; presente; (30) secção transversal: levemente corrugado; intermediário; corrugado; (31) número de lóculos: um; dois; três; quatro; cinco; (32) superfície do fruto: liso; semirrugoso; rugoso; liso com estrias; semirrugoso com estrias; (33) persistência entre fruto e pedicelo: pouco persistente; intermediário; persistente; (34) pungência: doce; picante baixo, picante médio; picante alto; (35) aroma: baixo; médio; alto; (36) número de sementes por fruto: menor de 20; 20 a 50; acima de 50.

Para as análises, foi considerada a moda de cada descritor para o grupo de acessos avaliados. Os dados obtidos foram submetidos à análise de divergência genética pelo procedimento para dados multicategóricos do programa computacional GENES (CRUZ, 2007). Essa metodologia consiste na obtenção de um índice em que são considerados vários caracteres simultaneamente, e cada caráter pode apresentar várias classes. Foi gerada uma matriz de dissimilaridade com base no complemento do coeficiente de coincidência simples. O índice leva em consideração a ocorrência e concordância de valores. A distância entre os genótipos i e j é dada pela fórmula $\mathrm{Dij}=(1-\mathrm{C}) /(\mathrm{C}+\mathrm{D})$, em que $\mathrm{C}$ é a concordância de valores, e $\mathrm{D}$ é a discordância. A partir das informações dessa matriz, os acessos foram agrupados pelo método de otimização de Tocher, utilizando-se o aplicativo computacional GENES (CRUZ, 2007). A análise de agrupamento baseada no método de Tocher tem por objetivo a formação de grupos em que os valores das distâncias intragrupos sejam inferiores a quaisquer distâncias intergrupos (CRUZ \& CARNEIRO, 2003). Ainda com essa mesma matriz foi realizado o

Ciência Rural, v.40, n.6, jun, 2010. 
agrupamento pelo método UPGMA (unweighted pairgroup mean average), para formação do dendrograma. Para essa análise, usou-se o programa computacional NTSYSpc 2.10t. (ROHLF, 1992). Nos métodos hierárquicos, os genótipos são agrupados por um processo que se repete em vários níveis, até que seja estabelecido um dendrograma (árvore de agrupamento). O UPGMA é um método não ponderado de agrupamento aos pares que utiliza médias aritméticas das medidas de dissimilaridade e evita caracterizar a dissimilaridade por valores extremos (máximo ou mínimo) entre os genótipos considerados (CRUZ \& CARNEIRO, 2003).

\section{RESULTADOS E DISCUSSÃO}

Dois descritores utilizados na caracterização morfológica foram monomórficos: constrição anelar do cálice e apêndice na ponta do fruto, sendo ambos ausentes em todos os acessos. Esses descritores foram excluídos da análise de dissimilaridade, sendo usados 34 na análise de divergência genética. Os descritores que apresentaram maiores diferenças de classes entre os acessos foram "espessura da parede do fruto" e "ombro do fruto", com cinco classes contempladas. A partir da matriz de distâncias entre as variáveis multicategóricas (dados não apresentados), os acessos foram reunidos em três grupos pelo método de otimização de Tocher (Tabela 2).

Os acessos foram reunidos em três grupos, conforme o método de otimização de Tocher (Tabela 2). Formou-se um grande grupo G1 composto pela maioria dos acessos (15 acessos). Todos os acessos de pimentão (P31, P45, P55 e P98) ficaram incorporados nesse grupo. Características comuns aos acessos do grupo G1 foram corola branca e fruto imaturo com coloração verde. A grande maioria possui hábito de crescimento ereto, apenas os acessos P43 e P51 são prostrados. A menor divergência entre acessos foi de

Tabela 2 - Agrupamento de 20 acessos de Capsicum annuum do banco ativo de germoplasma de Capsicum da Embrapa Clima Temperado, em Pelotas, RS, segundo o método de otimização de Tocher, baseado em 34 descritores morfológicos.

\begin{tabular}{ll}
\hline Grupo & \multicolumn{1}{c}{ Acessos $^{1}$} \\
\hline \multirow{2}{*}{ G1 } & P4, P5, P6, P31, P43, P45, P46, P47, P48, \\
G2 & P51, P55, P58, P76, P98, P111; \\
G3 & P7, P16, P22, P39; \\
& P77
\end{tabular}

${ }^{1}$ Ver a tabela 1 para identificação dos acessos.
18\%, encontrada entre P31 e P45 (dados não apresentados). Estas são duas variedades crioulas de pimentão, cultivados por diferentes agricultores da Ilha dos Marinheiros, no Município de Rio Grande, RS. Esses acessos apresentaram diferenças em seis descritores: presença de antocianina nodal, cor da antera, margem do cálice, secção transversal, número de sementes e pungência. Uma hipótese para explicar essa semelhança seria a de que esses acessos possuíssem a mesma origem parental e que os descendentes segregaram com poucas diferenças. Outra possibilidade seria a de que os genótipos cultivados próximos (mesma ilha) sofreram cruzamentos e, com o passar das gerações, provocaram mistura entre as variedades. LEFEBVRE et al. (1993) notaram que Capsicum annuum é altamente variável em comparação a culturas de autofecundação. Eles sustentam que a variação morfológica em $\boldsymbol{C}$. annuum pode ser explicada pelo seu modo de reprodução e processo pelo qual a espécie passou até a sua domesticação.

Os acessos provenientes da Tailândia (P4, P5 e P6), com 18 descritores em comum e a distância variando de 29 a 32\% (dados não apresentados), também fizeram parte do grupo G1. Ainda nesse grupo ficaram os acessos provenientes do Uruguai (P46, P47, P48) que foram monomórficos para 13 descritores. Os acessos P51 e P76, ambos vindos do México, o acesso P43, conhecido como pimenta pé-de-cachorro, de Tocantins, além de P58, P98 e P111 (jalapeño), são as pimentas que completam o grupo.

O grupo G2 é formado por acessos com potencial ornamental (P7, P22, e P39). São plantas de baixa estatura e com grande quantidade de frutos eretos. Durante a maturação, os frutos desses acessos passam por diversas cores. O acesso $\mathrm{P} 39$ possui frutos muito pequenos, redondos, eretos e de coloração vermelho-intensa quando maduros. SUDRÉ et al. (2005, 2006) recomendam acessos com essas características para serem utilizadas no melhoramento com finalidade ornamental. Três acessos (P7, P16 e P22) são oriundos da mesma região do Paraná. O acesso P16 é proveniente de uma variedade comercial de pimenta cayenne. As variedades locais doadas por agricultores possivelmente são cultivadas próximas umas às outras, oportunizando o cruzamento entre as plantas. Os agricultores frequentemente exercem uma forte pressão de seleção quando utilizam um limitado número de plantas com características de interesse. Ao longo do tempo, isso pode causar considerável erosão genética (PORTIS et al. 2004).

O grupo G3 foi formado exclusivamente pela pimenta-negra do México (acesso P77), caracterizado pela elevada concentração de antocianina em suas 
folhas, hastes, flores e frutos imaturos. Essa característica confere elevado potencial ornamental ao acesso. Diversos descritores, como folha verde com antocianina, haste violeta, flor ereta e corola violeta, característicos da pimenta-negra, contribuíram para que este formasse um grupo separado dos demais acessos.

Os dois pares de acessos mais divergentes foram P76 x P77, e P77 x P98. A diferença entre eles é de 79\% (dados não apresentados), por apresentarem diferentes classes para 27 descritores. No presente trabalho, a presença de um único acesso muito divergente (P77) pode ter influenciado a formação de apenas três grupos pelo método de Tocher e a colocação de 15 acessos dentro de um mesmo grupo. SUDRÉ et al. (2006), ao estudarem a divergência fenotípica entre 59 acessos de Capsicum utilizando 15 descritores qualitativos, obtiveram a formação de oito grupos pelo método de Tocher. NEITZKE et al. (2008) obtiveram a formação de oito grupos de Tocher a partir de 35 acessos.

No dendrograma, (Figura 1) foi considerada a dissimilaridade média entre os acessos como o ponto de corte a $52 \%$ no eixo das abscissas, sendo esta a distância relativa entre os acessos. Assim, foram formados quatro grupos. O dendrograma e o agrupamento pelo método de Tocher concordaram quanto à separação do acesso P77, expressa pela sua extrema divergência (66\%) em relação aos demais acessos (Figura 1).
Ambos os métodos (Tocher e UPGMA) foram parcialmente concordantes no que diz respeito à divergência genética dos demais acessos. SUDRÉ et al. (2005) encontraram pequenas diferenças na formação de grupos de acessos de pimentas e pimentões de acordo com o método utilizado. As diferenças encontradas entre os métodos podem ser explicadas pela maneira diferente que cada método tem de fazer o cálculo de variabilidade genética. Nesse caso, podem ser úteis análises realizadas com marcadores moleculares do tipo AFLP ou RAPD, que, em Capsicum, demonstraram maior capacidade de discriminação (GELETA et al., 2005).

O presente estudo demonstra presença de diversidade genética intraespecífica entre os acessos de $\boldsymbol{C}$. annuum do banco ativo de germoplasma da Embrapa Clima Temperado. Não foram identificadas duplicatas entre os 20 acessos; entretanto, houve a formação de um grupo que inclui grande parte dos acessos, inclusive originados de países diferentes (G1).

\section{CONCLUSÃO}

Os acessos são divergentes, demonstrando variabilidade moderada. Devem ser priorizados novas coletas e novos trabalhos de caracterização, a fim de diversificar e ampliar as possibilidades de uso em programas de melhoramento.

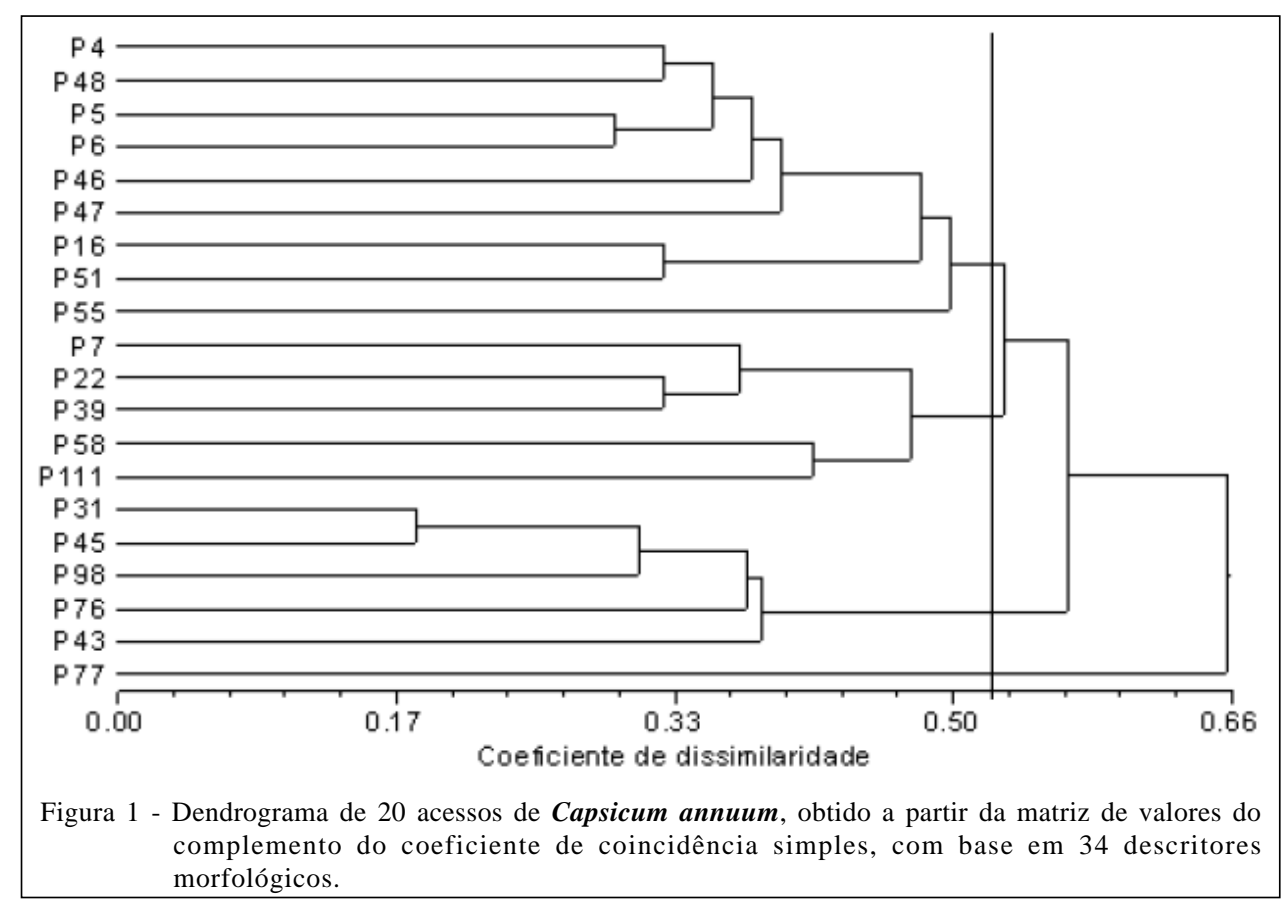

Ciência Rural, v.40, n.6, jun, 2010. 
Foram identificados acessos de plantas compactas, frutos eretos e que se destacam com a folhagem e frutos que passam por diversas cores durante o processo de maturação, podendo ser utilizados em programas de melhoramento com finalidade ornamental (acessos P7, P22, P39 e 77).

\section{AGRADECIMENTOS}

À Embrapa, pelo suporte financeiro, e ao Conselho Nacional de Desenvolvimento Científico e Tecnológico (CNPq) e à Coordenação de Aperfeiçoamento de Pessoal de Nível Superior (CAPES), pela concessão das bolsas de mestrado.

\section{REFERÊNCIAS}

BOSLAND, P.W.; VOTAVA, E. Peppers: vegetable and spice Capsicums. Crop production science in horticulture 12 Wallingford: CAB International, 1999. 204p.

CARVALHO, S.I.C. de et al. Catálogo de germoplasma de pimentas e pimentões (Capsicum spp.) da Embrapa Hortaliças. Brasília : Embrapa Hortaliças, 2003. 49p.

COSTA, F.R et al. Genetic diversity among Capsicum accessions using RAPD markers. Crop Breeding and Applied Biotechnology, v.6, n.1, p.18-23, 2006. Disponível em: <http://www.sbmp.org.br/cbab/siscbab/uploads/bd6ba09c-4aa3b62a.pdf $>$. Acesso em: 17 mar. 2010.

CRUZ, C.D. Genes: aplicativo computacional em genética e estatística. Viçosa: UFV, 2007. (Versão 2007.0.0).

CRUZ, C.D.; CARNEIRO, P.C.S. Modelos biométricos aplicados ao melhoramento genético. Viçosa: UFV, 2003, v.2, 585p.

GELETA, L.F. et al. Genetic variability in pepper (Capsicum annuum L.) estimated by morphological data and amplified fragment length polymorphism markers. Biodiversity and Conservation, v.14, p.2361-2375, 2005. Disponível em: <http://www.springerlink.com.w10048.dotlib.com.br/content/ b54v6l26h6184l7w/fulltext.pdf >. Acesso em: 15 fev. 2009. doi: $10.1007 /$ s10531-004-1669-9.

LEFEBVRE V. et al. Nuclear RFLP between pepper cultivars (Capsicum annuum L.). Euphytica, v.71, p.89-199, 1993. Disponível em: <http://www.springerlink.com/content/ ax71m56400182151/fulltext.pdf>. Acesso em: 18 jul. 2008. doi: $10.1007 / \mathrm{bf00040408.}$

MOREIRA, G.R.M. et al. Espécies e variedades de pimenta. Belo Horizonte: EPAMIG, 2006. v.27, p.16-29. (Informe Agropecuário).
NEITZKE R. S. et al. Divergência genética entre variedades locais de Capsicum baccatum utilizando caracteres multicategóricos Magistra, v.20, n.3, p.249-255, 2008. Disponível em: <http:// www.magistra.ufrb.edu.br/publica/20.3\%20 PDF/ 06_Divergencia_genetica_entre_variedades_locais.pdf $>$. Acesso em: 15 mar. 2010.

PICKERSGILL, B. Genetic resources and breeding of Capsicum spp. Euphytica, v.96, p.129-133, 1997. Disponível em <http:/ /www.springerlink.com/content/w1h5437x32531771/ fulltext.pdf>. Acesso em: 20 maio, 2008. doi: 10.1023/ a:1002913228101.

PORTIS, E. et al. Effect of farmers' seed selection on genetic variation of a landrace population of pepper (Capsicum annuum L.) grown in North West Italy. Genetic Resources and Crop Evolution, v.51, p.581-590, 2004. Disponível em: <http://www.springerlink.com/ content/t16h3561171gg0x1/ fulltext.pdf $>$. Acesso em: 20 maio, 2008. doi: 10.1023/ A: 1025075118200

REIFSCHNEIDER F.J.B. (Org). Capsicum: pimentas e pimentões do Brasil. Brasília: Embrapa Comunicação pra Transferência de Tecnologia; Embrapa Hortaliças, 2000. 113p.

ROHLF, F.J. NTSYS-PC: numerical taxonomy and multivariate analysis system. New York: Exeter Software, 1992. (Version 2.10t)

RUFINO, J.L. dos S.R; PENTEADO, D.C.S. Importância econômica, perspectivas e potencialidades de mercado para a pimenta. Belo Horizonte : EPAMIG, 2006. V.27, p.715. (Informe agropecuário).

SUDRÉ, C.P. et al. Divergência genética entre acessos de pimenta e pimentão utilizando técnicas multivariadas. Horticultura Brasileira, v.23, p.2-27, 2005. Disponível em: <http://www.scielo.br/pdf/hb/v23n1/a05v23n1.pdf>. Acesso em: 20 maio, 2008. doi: 10.1590/S010205362005000100005 .

SUDRÉ, C.P. et al. Variáveis multicategóricas na determinação da divergência genética entre acessos de pimenta e pimentão. Horticultura Brasileira, v.24, p.88-93, 2006. Disponível em: <http://www.scielo.br/pdf/hb/v24n1/a18v24n1.pdf>. Acesso em: 12 jul. 2008. doi: 10.1590/S010205362006000100018 .

TOQUICA, S.P. et al. Molecular characterization by AFLPs of Capsicum germplasm from the Amazon Department in Colombia. Genetic Resources and Crop Evolution, v.50, p.639-347, 2003. Disponível em: <http://www.springerlink.com/ content/x3t7108337755577/ fulltext.pdf $>$. Acesso em: $12 \mathrm{jul}$. 2008. doi: 10.1023/A:1024429320771. 